\title{
Processos de vida-formação na constituição da docência na educação profissional técnica
}

\author{
Graziela Ninck Dias Menezes \\ Instituto Federal da Bahia \\ Jane Adriana Vasconcelos Pacheco Rios \\ Universidade do Estado da Bahia
}

\section{Resumo}

artigo busca compreender como as experiências de vida-formação constituem a docência na Educação Profissional Técnica. Resulta de pesquisa (auto)biográfica a partir dos referenciais de Delory-Momberger (2012), Nóvoa (2007), Pineau (2014) e Souza (2014). Para a discussão da docência, recorreu-se a Gatti (20 1 1; 2011 a), Ramalho, Nuñes e Gauthier (2004), Rios (2014) e Souza e Nascimento (20 1 3). Como procedimento metodológico, foi utilizada a entrevista narrativa com seis docentes do Instituto Federal da Bahia/Campus Ithéus. Como resultados, aponta a relevância dos processos experienciais na constituição da docência, bem como a necessidade de observância desses processos no desenvolvimento da política de formação dos profissionais licenciados e bacharéis que adentram os Institutos Federais de Educação.

Palavras-chave: Docência. Vida-formação. Educação profissional técnica.

\section{Life-training process in the constitution of the teaching in professional technical education}

\section{Abstract}

The article discusses how the experience of life-training contributes the teaching at the Professional Technical Education. Results of (auto) biographical research from references to Delory-Momberger (2012), Novoa (2007), Pineau (2014) and Souza (2014). On the discussion of the teaching we used Gatti (201 1; 2011 a), Ramalho, Nuñez and Gauthier (2004), Rivers (2014) and Souza and Nascimento (2013). As methodological procedure, we gave employed narrative interviews with six teachers of the Federal Institute of Bahia/Iheus Campus were used. As a result, the work points out the relevance of experiential processes in the constitution of teaching as well as the need to observe these processes in the development of training policy for licensed professionals and bachelor professionals who step into the Federal Institutes of Education.

Keywords: Teaching. Life training. Professional technical education. 


\section{Procesos de vida-formación en la constitución de la docencia en la educación profesional técnica}

\section{Resumen}

El artículo discute como las experiencias de vida y formación técnica constituyen la docencia en la Educación Profesional Técnica. Resulta de una metodología autobiográfica desde las referencias de Delory-Momberger (2012), Novoa (2007), Pineau (2014) y Souza (2014). A respecto de la discusión sobre la docencia utilizamos Gatti (201 1; 201 1a), Ramalho, Nuñez y Gauthier (2004), Rivers (2014) y Souza y Nascimento (2013). Como procedimiento metodológico se utilizó las entrevistas narrativas con seis maestros del Instituto Federal de Bahía Campus/llheus. A consecuencia apunta la relevancia de los procesos experienciales en la constitución de la docencia, bien como la necesidad de la observancia de esos procesos en el desarrollo de la política de formación de los profesionales licenciados o con bachilleratos que entran en los Institutos Federales de Educación. Palabras clave: La política educativa. Financiación de la educación. Sueldo de los profesionales de la enseñanza.

\section{Introdução}

presente texto resulta de um processo investigativo desenvolvido com professores de um campus do interior do Instituto Federal da Bahia/ Campus Ilhéus, buscando compreender como as experiências de vida-formação constituem a docência desses professores.

Para tanto, desenvolveu-se um procedimento teórico-metodológico que perpassa pelos estudos da pesquisa autobiográfica, compreendendo a docência como uma produção de sujeitos frente aos encontros, desafios e superações de cada pessoa-professor no seu fazer pedagógico e na sua própria vida, portanto, a docência como resultado do encontro da atividade educativa e com outras tantas atividades que constituem os professores.

trabalho foi desenvolvido com seis professores de dois cursos Técnicos de Nível Médio Integrado. Considerando que os professores são organizados por área de formação, selecionou-se um professor de cada área propedêutica (Linguagens, Ciências da Natureza e Matemática, Ciências Humanas), um professor da área diversificada e um professor de cada curso 
técnico, sendo estes os cursos de Informática e de Segurança do Trabalho. Além disso, constituiram-se, também, critérios para seleção dos professores: pertencer ao quadro do campus, no mínimo, por um ano; ter experiência profissional em outros cenários além da docência; ter experiência como docente em outros locais ou campi do IFBA.

Para a recolha das histórias de vida-formação dos docentes utilizaram-se as entrevistas narrativas, as quais foram concebidas como espaço de construção e atualização do vivido, delineado pelos sentidos que os sujeitos atribuíram às suas experiências de formação. Além disso, as narrativas revelaram a condição autoformativa, ao permitir que os sujeitos falassem de si a partir do movimento de reflexividade que constitui o processo de narração, podendo desvelar os processos que formam os modos de exercer e viver suas docências no âmbito da Educação Profissional Técnica.

A transcrição das narrativas e sua análise ocorreram num movimento de leitura e releituras observando os acontecimentos narrados para compreender a trama que envolve os sujeitos e o contexto social. Com base nos estudos de Souza (2014), procedeu-se à análise em três tempos: Tempo I - momento de produção do perfil biográfico individual e coletivo dos sujeitos; Tempo II 88 - identificação das regularidades, irregularidades e singularidades expressas nos acontecimentos biografados pelos sujeitos e observados nos cruzamentos das narrativas; Tempo III - interpretação dos acontecimentos e da trama construída a partir do suporte teórico estabelecida para a pesquisa.

Compreender a docência, nesse campo educacional, implicou empreender uma leitura sobre os processos subjetivados pelos professores, constituintes de suas identidades docentes. Assim, o modo como as experiências (BONDÍA, 2002; JAY, 2009) de vida junto à família, à escola básica e à academia colaboraram para a formação da identidade docente desses professores, foi analisado como espaço de ecoformação, heteroformação e autoformação, campos fundantes do processo de formação docente, a partir da teoria tripolar de Pineau (2014).

Esses três movimentos formativos implicam pensar que as pessoas se constituem a partir da relação com o outro, com o mundo e consigo mesmo, sendo o movimento reflexivo que o sujeito faz o espaço de autoprodução diante da ação dos outros e do meio onde vive. 


\section{Das experiências familiares às travessias escolares}

Compreendendo que os modos de ser, de fazer e de sentir dos professores são marcados pelo enlace entre o contexto social e as formas de apropriação individuais que os docentes produzem diante do cenário vivenciado, considerou-se que os sujeitos falam sempre de uma condição biográfica (DELORY-MOMBERGER, 2012) que os insere como sujeitos; ao mesmo tempo, em que são singulares, também são coletivos, porque carregam as marcas da historicidade que os perfazem.

Desse modo, considerar, neste trabalho, o processo formativo e constitutivo da docência, pressupõe compreender o professor como sujeito ativo no mundo, que se constrói diante do vivido, marcado por uma subjetividade que the institui uma potência para significar e produzir o mundo onde se encontra.

Os professores que participaram como sujeitos da pesquisa deste trabalho revelaram que o papel da família na valorização e garantia da formação escolar, sobretudo, na infância, foi um traço comum entre eles. A ideia de garantia da escolaridade para os filhos como possibilidade de ascensão social é reconhecida pelos professores como tentativa dos seus pais de não permitir que o contexto econômico que os atingiu limitasse seus processos de desenvolvimento educacional. A família também foi agente promotor de saberes, influenciando os sujeitos a reconhecer a educação como potencialidade de vida socioeconômica e profissional. Tal aspecto é exemplificado na narrativa da professora Artemis':

[...] meus pais sempre priorizaram a educação, no sentindo de legado mesmo, então, meus pais sempre disseram que não teriam patrimônio para me deixar, mas que me deixariam educação, e eu tenho tentado trilhar esse caminho de profissional, de vida, e de realização pessoal (ARTEMIS, 2014).

Nessa passagem, a professora Artemis revela como o valor da educação constituiu um legado para si e como assume isso enquanto saber e como direcionamento pessoal na busca pela formação profissional. Observou-se que, como movimento de autoformação, ela foi produzindo os mecanismos de ałuação frente ao contexto da ecoformação que ali acontecia e que perpassou a vida da professora em todos os campos, visto que, ao lidar com os limites 
econômicos da família, fez desse cenário um campo de produção de sentidos que a levou a dedicar um espaço importante para a educação na sua vida.

Nas narrativas dos docentes colaboradores, é evidenciado como as experiências produzidas junto à família e no processo de escolarização fortalecem os sentidos que os sujeitos construíram sobre o conhecimento e a educação formal. Observou-se, ainda, que é manifestado pelos professores como essa relação ultrapassou a cada um deles e se constituiu em um projeto de realização da família e de investimento como mecanismo de enfrentamento e superação das dificuldades socioeconômicas. Isso é possível constatar na narrativa do professor Apolo:

A minha infância foi tranquila, eu trabalho desde cedo, isso me deu um senso de responsabilidade muito grande, a gente sempre foi uma família: pai, mãe e mais quatro filhos. Meu pai sempre trabathava e a gente sempre ia para feira nos finais de semana. Então digamos que a gente nunca teve final de semana assim, porque tinha sempre que trabalhar final de semana. Então a gente sempre foi muito responsável pelas coisas que eram propostas, principalmente em questão à educação, por mais que a gente não tivesse tudo, nem escolas particulares isso era sempre muito valorizado. A gente sempre teve esse senso de que a educação podia mudar a nossa realidade, nossa só não, mas da família em si (APOLO, 2014).

O professor revela como a questão socioeconômica atravessou a vida da sua família e que a educação foi concebida como vetor de transformação da realidade à qual estava submetido, inclusive pelo trabalho que chegou à sua vida já na infância, quando colaborava nos fins de semana no trabalho que seu pai exercia como comerciante na feira livre. Nesse sentido, a escolarização foi a alternativa encontrada pela família de Apolo como mecanismo de alteração daquela realidade.

Uma característica marcante na relação família-escola, presente nas narrativas de formação dos professores, colaboradores desta pesquisa, foi a realização pessoal dos pais na ascensão escolar dos filhos, implicando um investimento financeiro e emocional dos pais, que não tiveram, em suas trajetórias de vida, a possibilidade de ter acesso à escola básica e/ou ao ensino superior. Como se pode observar na narrativa do professor Hefesto-Andejo, ao afirmar que seus pais buscaram proporcionar aos filhos uma educação que 
eles não puderam ter, uma vez que "[...] a ideia deles era estar nos dando base para o que nenhum dos dois conseguiu [...] que era o sonhado curso de nível superior".

No que se refere ao valor e acesso à educação básica promovidos no seio familiar, observou-se, no decorrer das narrativas de todos os professores-colaboradores, que a família é um espaço de eco e heteroformação que contextualiza as influências possíveis para que esses sujeitos se tornassem pessoas escolarizadas e tivessem referências de valores positivos sobre o processo educacional, já que as famílias, a partir das relações sociais e afetivas estabelecidas com os sujeitos, promovem, para eles, sonhos, desejos, necessidades.

As experiências construídas nas relações com o contexto e com os outros na escola básica constituem campos de produção da dimensão autoformativa dos sujeitos. Um traço em comum entre os professores Apolo e Hefesto-Andejo era a condição de líderes em grupos de trabalhos escolares, que os colocava em situação de orientação, exposição de temáticas de estudos. Assim, a presença dos colegas e os desafios dos trabalhos em equipe e do compartilhamento de saberes thes possibilitaram produzir significados para as práticas de estudo e aprendizagem, como revela o professor Hefesto-Andejo:

[...] eu era o sujeito que estava explicando aos outros como é que se fazia, eu era o sujeito que preferia tomar para mim o trabalho e fazer quando eu via que os outros com menos desenvoltura para realizar um trabalho que era de equipe, que se eu estava naquela equipe que tinha que fazer e sair bem feito, eu tomava o prejuízo de chamar o trabalho para mim a despeito do tempo. De ter quem fizesse, de ter quem dividisse a tarefa comigo, então isso da elaboração intelectual das tarefas que acompanha o docente eu tive desde sempre (HEFESTO-ANDEJO, 2014).

professor narra como, na relação com os pares, desenvolveu o que ele mesmo define por "tarefa intelectual do docente". A presença do outro The permitia o exercício do diálogo, da orientação e da mediação pedagógica. Saber ensinar é uma dimensão importante do processo de educar e que caracteriza o trabalho docente. Enquanto narra, o professor Hefesto-Andejo vai reafirmando como o aprender a ser professor foi se construindo, dialeticamente, na relação com os colegas da escola básica, nos grupos sociais que constituiu ao longo de sua trajetória formativa. 
Assim, procura-se enfatizar como a heteroformação atravessa a constituição da docência do sujeito, visto que revela como o espaço de interação, de solicitações, de reconhecimento de si pelo outro produziu um modo de relação pessoal com os pares e com o universo da escola e das relações de ensinar-aprender. Essa é uma aprendizagem que se encarna a partir do modo de ser de cada um. Entre as principais referências de formação dos docentes, nesse período, está a figura do professor da educação básica na identificação com a escolha da profissão docente, como se pode observar na narrativa do professor Apolo:

[...] eu tinha uma figura muito perfeccionista dos professores, eu sempre endeusava, achava que assim eram semideuses, eu tinha ela como deusa, eu tinha uma visão sobre professor bem perfeita, tanto é que eu virei professor. [...]. Mas sempre tive muita admiração, tanto pelo professor quanto pelo ambiente escolar, isso talvez tenha influenciado na escolha da profissão no futuro (APOLO, 2014).

Enquanto narra, o professor vai revelando como as marcas do outro e a experiência construída nessa relação é formadora do modo de ser, da defi92 nição de como o sujeito se vê e se projeta a partir das referências construídas, caracterizando, assim, um movimento de constituição de sua subjetividade. Assim, ser professor na vida de Apolo, é uma escolha traçada pelo modo como ele internalizou a profissão a partir da sua experiência como aluno.

Outra narrativa que se destaca é apresentada pela professora Artemis ao tratar dos desafios do contexto em que vivia. Ela mostra, na experiência narrada, como enfrentou uma situação de preconceito dentro do ambiente escolar. Ela diz:

[... na Educação básica eu cheguei a ouvir não só de um professor, mas de vários que eu nunca iria a lugar nenhum, porque eu morava na cidade em periferia, porque meus pais [...] Meu pai é negro, eu me reconheço como afrodescendente, minha avó é negra, meu pai é negro de pele, eu não sou negra de pele, mas sou negra de descendência, então até isso eu já ouvi, uma das coisas do bullyng era isso, a questão étnica racial, e eu escolhi não me abalar (ARTEMIS, 2014).

Durante sua narrativa, a professora Artemis discorre como viveu a situação de preconceito étnico e social na escola, por ser da periferia e 
afrodescendente. Mas, a sua atitude de não permitir que tal situação a imobilizasse, mostra que o sujeito, dominando os processos que lhe constituem, constrói seus caminhos e pode reorganizar os elementos que o rodeiam, colocando-se como sujeito em acontecimento. Segundo Rios (2014, p. 278), " [...] todo processo de formação cruza, à sua maneira a temática da existencialidade associada à questão da identidade". Isso também aponta o que Pineau (2014) define enquanto a dimensão autorreferencial produzida pelo sujeito no seu processo formativo.

destaque das dimensões de gênero, etnia e condição social, presentes no início da narrativa da professora Artemis, é apresentado por ela para mostrar que sua busca era por agir, contrariamente, ao meio em que vivia. Ela não revela a escolha pela docência por uma dimensão idealizada da profissão ou pela influência das relações vividas no período escolar. $\bigcirc$ que afirma é o valor da educação para si como mecanismo de saída da condição social e econômica em que se encontrava. Nas palavras de Nóvoa (2007, p. 16), "[...] a construção de identidades passa sempre por um processo complexo graças ao qual cada um se apropria do sentido da sua história pessoal e profissional".

É evidenciado, nas experiências narradas, que a família e a escola básica são pilares fundamentais no processo de constituição da docência. Elas movem e fundam os valores, os interesses pelos quais os sujeitos, em primeira instância, guiam seus caminhos, revelando marcas que contribuíram para que a docência fosse um horizonte e uma escolha em suas vidas, portanto emergente das relações ativas produzidas no contato com o outro e com o meio, bem como da apropriação das experiências que foram produzidas. Nesse sentido, compõem o espaço de hetero, eco e autoformação dos professores que têm, na formação básica e familiar, os alicerces de suas histórias de vida.

\section{Modos de se constituir professor na licenciatura}

Os professores colaboradores desta pesquisa, que optaram pela licenciatura na formação acadêmica inicial, relatam como essa opção é marcada por processos pessoais e condicionantes sociais nos quais estavam imersos. Assim, a opção pela docência é, mais uma vez, marcada por processos identitários que vão delineando os modos de se constituir professor. 
No caso da professora Artemis, o curso de Pedagogia foi fundamental para sua profissão, mas a inserção da pesquisa através da Iniciação Científica fez a diferença no seu desenvolvimento profissional:

[...] a faculdade era particular, não supria os meus anseios nesse sentido, fiz o curso, concluí, sou licenciada em Pedagogia com enfoque em Administração Escolar e Magistério das séries iniciais, [...] Mas, assim, no final do terceiro ano, no começo do terceiro ano, eu já fiz Iniciação Cientifica na faculdade com bolsa, isso foi bom para mim porque me preparou, minha professora era doutoranda da UNICAMP e aí ela me apresentou a Ciência do jeito que eu achava que deveria ser, como a faculdade não tinha me mostrado, aqueles trabalhinhos aquelas coisas. E aí ela me apresentou essa docência, essa Ciência, esse método de investigação (ARTEMIS, 2014).

A professora Artemis revela, na fala acima, um elemento que percorre toda sua narrativa, quando atribui qualidade à formação do sujeito via o rigor científico, estabelecendo crítica ao modelo formativo que tinha durante as disciplinas da graduação. Essa qualidade que atribui ao rigor científico 94 é expressa em vários momentos, inclusive no seu processo de graduação e pós-graduação, sobretudo, pela relação que estabelecida entre docência-ciência-investigação, ao falar "E aí ela me apresentou essa docência, essa Ciência, esse método de investigação".

Tal questão se reporta à discussão proposta por Ramalho, Beltran e Gauthier (2004), quando mostram o valor da pesquisa no processo formativo docente, ao poder aproximar o conhecimento teórico da realidade escolar e potencializá-la como situação-problema de modo sistemático. As teorias devem constituir ferramentas de reflexão e pesquisa sobre a práxis educativa, sendo isso tomado como exigência para uma formação universitária inicial a partir de uma identidade docente que se quer formar, permeada de finalidade e objetivos de ação, ou seja, que exige definir qual é o núcleo da profissão.

Cabe destacar que a trajetória formativa da professora Artemis, no campo da educação, é alterada pela leitura que faz da atitude dos colegas que lecionavam no ensino fundamental das séries iniciais em uma escola da área rural, um dos espaços onde começou atuar. Ela relata que via, nos modos como os colegas produziam a profissão, um movimento de descompromisso 
com o fazer e não gostaria de compactuar com tal situação, resolvendo buscar outra licenciatura:

E aí fazendo o curso de Pedagogia nesse paralelo eu percebi que não era isso que eu queria, me debater a vida inteira com colegas que achavam que o seu trabalho que precede ao meu em termos de série, não precisa ser bem feito. E ainda mais naquela realidade tinha muito o discurso [... 'Eles precisam saber ler, escrever e contar'. Então o que eu não queria para mim eu não queria para os meus alunos eu achava que eles podiam mais. Então essa realidade foi me desgastando muito e ao terminar, ao chegar ao terceiro ano de Pedagogia eu falei: não quero isso para mim, e passei a cogitar fazer uma graduação (ARTEMIS, 2014).

A professora Artemis ratifica a importância do processo reflexivo como vetor da construção da atitude profissional para a docência e potencializador de transformações que o sujeito faz a partir de suas determinações. Descontente com o sentido ético que percebia presente nas práticas dos pares e, como isso a afetava, sua saída foi buscar outro campo de atuação via uma nova graduação. A professora revela, em outro trecho da narrativa, que, por questões de logística, optou por uma instituição próxima à sua casa, onde cursou Geografia, descobrindo afinidade com o campo de estudo durante sua formação. Nas palavras de Nóvoa (2007, p. 16), sua posição como docente é um processo de "[...] adesão a princípios e a valores", resultante da construção de uma identidade considerada como um "[...] lugar de lutas e conflitos, é um espaço de construção de maneiras de ser e estar na profissão".

Nesse âmbito, o professor Apolo, também licenciado, revela sua experiência formativa, narrando como se deu esse processo no seu curso de Licenciatura em Física:

Então, essas foram formações eu digo conteudistas, elas não foram em relação à docência. Eu sempre digo que formação enquanto a professor a gente na disciplina de Física I, II e III, porque o curso era para licenciado e sempre falava que a gente seria professor, que era muito importante ser professor de Física, que tinha muito poucos professores formados, então esse era um discurso que ele sempre usava em relação ao fato de ser professor [...] A gente também começou a discutir sobre ser professor durante a Iniciação Científica, já que a gente trabalhava na área de ensino e experimentação em Física, mas, especificamente mesmo, a partir do sétimo, 
oitavo com disciplinas específicas, Metodologia e Instrumentação, e os estágios na área de Física (APOLO, 2014).

Na narrativa do professor Apolo, fica explícito que ele também vivenciou experiências formativas ligadas à pesquisa em educação por meio da Iniciação Científica, bem como participou de discussões sobre metodologia de ensino. Entretanto, o docente aponta que tais experiências se deram ao final do curso, a partir do sétimo e oitavo semestres, em disciplinas específicas.

Cabe notar que o professor Apolo faz sua graduação no início da década de 2000, quando foram promulgadas as Diretrizes Curriculares Nacionais para a Formação de Professores para a Educação Básica², que vão exigir uma ariculação mais efetiva entre o campo teórico disciplinar e a formação dos conhecimentos pedagógicos, próprios para a docência na educação básica, estabelecendo vínculo entre ensino e pesquisa. Percebe-se, a partir da narrativa do professor Apolo, que, no processo de Iniciação Científica do qual participou, há experiências formativas no curso acadêmico que buscaram estabelecer essa relação entre pesquisa e ensino. Entretanto, ele também indica que teve disciplinas e participou de eventos caracterizados por ele como "con96 teudistas", confirmando que se distanciavam da formação docente, ao dizer que essas formações "não foram em relação à docência".

Compreende-se que o professor Apolo viveu uma experiência formativa que, em seu conjunto, foi divergente daquilo que era preconizado nas Diretrizes Curriculares Nacionais para a Formação de Professores para a Educação Básica (BRASIL, 2002). Apesar das diretrizes em vigor, a experiência narrada revela uma distância entre a materialidade das bases dessas diretrizes e o processo vivido pelo professor.

Quanto à sua iniciação na docência, o professor Apolo demarca que iniciou sua experiência como professor em um pré-vestibular vinculado a um programa de ação afirmativa, em que já se sentiu responsável por uma turma, relatando que

Foi a primeira vez que entrei na sala de aula como responsável por uma turma de fato. Eu comecei dando aula de matemática, esses três primeiros anos de docência, não era uma turma digamos padrão assim, padrão você tem que avaliar, fazer prova. Era um curso pré-vestibular popular, você tinha que dar aula, mas você não tinha que se preocupar com avaliação. A primeira experiência 
para mim foi bacana você ser responsável por uma turma, e você entrar numa sala de aula a primeira vez, eu tinha dezessete anos, era até esquisito porque muita gente era mais velho que eu. Então você entrar numa sala de aula como responsável por uma turma, as pessoas te tratar como professor e já te dar certa responsabilidade (APOLO, 2014).

Aqui, o professor Apolo diz como a experiência de se sentir professor está atrelada à responsabilidade e ao papel imputado a ele no curso pré-vestibular onde lecionava. Ele afirma que ter uma turma de alunos sobre a qual ele tinha responsabilidade o fez sentir-se professor.

Desse modo, mesmo em um contexto distante da escola básica e da academia, o professor Apolo foi constituindo sua docência, atravessado pela dinâmica da ecoformação, considerando que as relações de trabalho num determinado contexto e o espaço que ocupou nestas, ainda aos dezessete anos, podem gerar experiências de trabalho, de exploração de uma profissão, do modo de ser, sentir e fazer docência.

As experiências formativas dos professores colaboradores que são licenciados apresentam reflexões sobre as referências formativas desses sujeitos. Assim, fica claro que as instituições de ensino superior não são o centro da formação de um professor e que, quanto mais elas puderem dialogar com as demandas reais da escola básica na articulação ensino, pesquisa e extensão, mais elas promoverão o empoderamento dos docentes e dos futuros docentes sobre seu processo formativo.

No campo das licenciaturas dos professores, as narrativas conduziram até aqui à compreensão de que, política e pedagogicamente, o projeto educacional brasileiro é fruto de muitas disputas e embates sobre a compreensão do que consiste o fazer dos professores e como os sujeitos escolhem e aderem a essa profissão.

que se constata é que as licenciaturas, nas universidades brasileiras, vêm passando por processos de ressignificações e mudanças, visando qualificar melhor os docentes da educação básica. É uma disputa entre um paradigma que pensa a formação como condição alheia ao sujeito, portanto toma o professor como objeto do processo e a emergência de novas discussões que refletem o professor não como consumidor de saberes prontos e acabados, 
mas como produtor de novas práticas, de sentidos e técnicas sobre seu fazer, e, ainda, enquanto sujeitos, carregam marcas de suas experiências indeléveis.

Outro ponto a ser pensado é que, se há distância na formação desses professores com a escola básica, nada é mencionado ao longo de suas narrativas sobre a educação profissional como campo de atuação dos licenciados, portanto, esses professores que, hoje, atuam nos Institutos Federais não foram contemplados em sua formação com discussões que promovessem reflexões sobre as demandas específicas de uma prática educativa no ensino médio vinculada à formação profissional.

Gatti (201 1) adverte que a universidade precisa ser preparada para desenvolver pesquisas e modelos formativos em parceria com educadores que desenvolvem uma prática educativa cotidiana e estão imersos nas demandas concretas das escolas, pois, distante destas, a formação reporta-se a um modelo de professor abstrato e genérico.

Esse professor precisa ser pensado como sujeito com identidades múltiplas, forjadas também nas suas experiências pessoais e acadêmicas. Desse modo, a escolha feita pelos professores Artemis e Apolo pela profissão docente, no âmbito da formação acadêmica, revela as redes de relações e circunstâncias que os guiaram e os fizeram constituir-se como pessoas singulares nos modos de produzir a formação inicial docente numa dinâmica entre sua constituição pessoal e profissional, gerando modos próprios de produzir a identidade profissional.

\section{Do bacharelado à sala de aula}

A pesquisa em pauta também ouviu professores com formação em bacharelado, dada a natureza do âmbito de trabalho desses profissionais na formação técnica. As experiências formativas dos professores bacharéis atestam que o processo da docência não se encerra, tão pouco inicia com a formação acadêmica, mas atravessam outros percursos como os caminhos percorridos pelos professores na sua iniciação profissional.

Nesse contexto, a identidade profissional não é um construto acabado, mas um processo redimensionado a cada movimento experiencial com o qual o sujeito se depara, modificando, também, o modo como se reconhece e se faz reconhecido pelo outro, sendo, então, produção de fluidez, instabilidades e transformações. 
Encontrar nas histórias formativas dos professores bacharéis os movimentos que os levaram à docência implica compreender que a profissão professor é determinada pelos acontecimentos, pelo devir da condição humana pessoal e profissional que acontece aos sujeitos.

Nessa direção, o professor Ares revela que foi numa relação de proximidade com dois professores e, a partir das imagens produzidas por estes sobre a docência, que ele foi mobilizado e orientado para a profissão de professor. Ele explicita como o contato com a experiência do outro (heteroformação) foi importante nessa escolha e, a partir desta, passou a pleitear a carreira docente para si. Assim, ele recorda:

[...] teve em especial dois professores na minha vida acadêmica que foram meus orientadores em projetos desenvolvidos na UESC, e professores de sala de aula. Então eles... 'você tem um perfil interessante, consegue falar bem, tem paciência...' eles foram citando em várias conversas que a gente foi tendo ao longo do tempo, características que podiam me tornar um bom professor [...] e pelo - que eles conversaram comigo eles disseram que tinha... como é que posso dizer... ter a cabeça organizada para elaboração de trabalhos acadêmicos. $E$, também, a questão de organização e planejamentos as atividades expositivas, eles falaram que eu tinha facilidade de falar da área de programação de computadores, que é um pouco difícil para o pessoal da área de exatas, eles identificaram naquele momento que eu tinha uma habilidade para falar sobre esse tipo de assunto no meio acadêmico (ARES, 2014).

$\bigcirc$ processo de reconhecimento aqui apresentado por Ares também evoca a questão do reconhecimento da identidade docente a partir de características definidas pelo outro como aquelas que são reconhecidas socialmente pertencentes ao domínio da profissão docente. Portanto, ter paciência, organização, planejamento, capacidade de exposição oral, foram reconhecidos como elementos pertinentes à docência. Assim, a imagem que o professor Ares vai compondo de si mesmo, como futuro professor, emerge de uma identidade coletiva que ele ressignifica em sua subjetividade.

É preciso constatar que a docência, para o professor Ares, não passou a ser uma carreira secundária ou paralela, mas uma opção de mudança profissional. Logo, a opção pelo ingresso na docência também é uma ressignificação da própria identidade da pessoa-professor de Ares. Segundo Gatti 
(201 1a, p. 162), "[...] associadas à identidade estão as motivações, os interesses, as expectativas, as atitudes, todos elementos multideterminantes dos modos de ser de profissionais".

Já o professor Hefesto-Andejo, formado em Arquitetura, revela outros caminhos que o levaram à docência, o que passou pela condição na qual exercia a profissão ligada à sua formação inicial. $\bigcirc$ professor revela que sua formação foi multirreferencial, marcada por um currículo vasto. Porém, essa condição foi construída por ele, uma vez que era permitido agregar disciplinas e estudos de áreas diferentes ou correlatadas ao seu curso de graduação. Assim, ele fala:

[...] eu peguei um sem número de disciplinas eletivas e optativas porque me interessava muita coisa. Então fui aluno na FACOM no curso de Jornalismo, fui aluno em Belas Artes e outras disciplinas, fui aluno dentro da própria faculdade de Arquitetura de matérias que não eram obrigatórias. Então, eu queria saber mais, queria conhecer coisas que eram da minha oportunidade naquele momento e, quando eu saísse, não iam estar mais ao meu alcance. [...] Claro, que de modo prático, a gente sabe da afinidade das discussões, mas a graça era poder passear pelo assunto dado por todos eles. Não tinha uma matéria que eu não gostasse ou que eu gostasse mais. Era bacana estar percorrendo tudo (HEFESTO-ANDEJO, 2014).

Em sua narrativa, o professor Hefesto-Andejo enfatiza o aspecto plural que construiu na sua formação. Demonstra como a condição de abarcar diversas referências teóricas na sua formação era algo que lhe satisfazia quanto ao interesse de aprender mais. Mas, também demonstra que compreendia as discussões como afins, portanto, revela que era uma busca intencional, correlata ao seu processo formativo. Contudo, no desenvolvimento de sua profissão como arquiteto, ele diz que não conseguia atuar na carreira e, apesar de estar desenvolvendo uma atividade que dependia de sua formação inicial, ele não conseguia exercer, de fato, a profissão para a qual foi formado. Assim, ele narra:

Eu não tinha conseguido fazer a minha própria arquitetura e me frustrei com a parte da experiência comercial de estar organizando a empresa, me relacionando com cliente, estimando valor para meu próprio serviço [...] E eu consegui fazer o acompanhamento dessa 
arquitetura que acontecia na minha frente, fazendo uma coisa também que eu gostava que era fotografar [...]. Foi marcante para mim na profissão ter convivido com Lelé! Que é um arquiteto, foi um arquiteto genial, eu passei mais tempo convivendo com ele, sem ter tido a oportunidade de desenvolver projeto, porque os projetos dele o traço é unicamente dele (HEFESTO-ANDEJO, 2014).

Aqui, o professor Hefesto-Andejo mostra como enfrentou dificuldades para exercer seu trabalho de arquiteto. Numa tentativa comercial, fala de frustrações e, apesar de considerar marcante outra experiência profissional, reconhecendo que sua formação era importante para o trabalho que realizava, afirma que isso não the permitiu espaço para criar, desenvolver projetos ou imprimir seu traço arquitetônico.

É com essa condição pessoal, formativa e profissional que a docência chega para o professor Hefesto-Andejo como um acontecimento, uma bifurcação ou desvio de um caminhar profissional outrora pensado. Narra que sua entrada para docência acontece a partir de um convite muito inesperado: "[...] e surgiu o convite para a docência, que foi uma coisa caída do nada e foi uma transferência assim imediata de realidade. Saí de um universo e caí em outro universo". Neste trecho da narrativa do professor é revelado que a entrada na docência não foi planejada, e representou uma mudança na sua vida e que tal mudança também ocorreu do ponto de vista geográfico, visto que o convite foi para uma instituição privada de ensino superior em outro estado brasileiro.

As histórias dos professores Hefesto-Andejo e Ares indicaram como os sentidos produzidos por eles sobre suas experiências os trouxeram até a docência, ainda que esta não tenha sido a opção inicial de formação e de profissão. Tornar-se professor é, então, uma possibilidade dada pelas suas marcas de experiências vividas.

Observou-se como os professores são acometidos pelos acontecimentos em suas vidas e como muitos desses elementos são promotores dos sentidos que são atribuídos à docência. Assim, a entrada na docência vai sendo produzida por caminhos diferenciados e promovendo aprendizagens também diversas. A decisão de ingressar na docência coloca o professor Hefesto-Andejo em novo desafio, pois foi mobilizando seu processo identitário na medida em que a vida profissional, os desafios das práticas cotidianas, as demandas sobre o trabalho pedagógico geraram outros movimentos formativos. 
Nesse sentido, o professor Hefesto-Andejo afirma que teve de sair de um universo e entrar em outro, chama atenção para a experiência que viveu da entrada na docência em uma instituição de ensino superior privada sem nenhuma preparação. Ao relatar esse processo, ele conta o quanto essa circunstância foi marcante em sua vida:

Já dentro de um curso de Arquitetura com mil e uma dificuldades, com um currículo diferente do meu, tendo que me deparar com conhecimento que eu não tinha tido na minha formação, então foi uma época de estudo assim desesperadora, mas foi muito bacana. [...] "Não vou ser professor!" foi o momento da maior angústia da minha vida foi aí. [...] porque eu estava tendo que me ocupar de aprender e, compulsoriamente, ensinar algo que estava sendo um aprendizado muito recente pra mim, tão recente que às vezes era da noite anterior (HEFESTO-ANDEJO, 2014).

Nessa passagem da narrativa, o professor Hefesto-Andejo mostra como o encontro com a docência foi um choque para ele. Sua entrada implicou lidar com a produção de conhecimento para si, bem como construção de mecanismos para o diálogo na formação com os alunos. Mostra que sua 102 identidade como professor foi forjada num movimento de ter que lidar com a relação de ensino-aprendizagem, processo descrito por ele como desesperador e angustiante. Marca que esse processo implicou uma condição de aprender de modo compulsório, já que se viu frente a conteúdos que não estavam no seu currículo de formação.

Assim, sem formação acadêmica específica, os docentes bacharéis são entregues a sua própria realização e tem sua experiência formativa como principal legado para produzir sua prática educativa.

Cabe destacar, conforme Souza e Nascimento (2013), que, diante da necessidade de formar profissionais para atuar no campo da produção de ciência e tecnologia, os Institutos Federais buscam um perfil de profissional qualificado pela sua vinculação com a área de trabalho, portanto, os bacharelados se apresentam como cursos superiores de formação generalista, científica e humanística que formam sujeitos para desenvolver competências em certos campos de saber e exercer essa prática no âmbito acadêmico, profissional e cultural. 
Já os cursos superiores tecnológicos ofertam formação para a atuação em áreas profissionais muito específicas (BRASIL, 2010). Entretanto, observa-se que as experiências pessoais e os caminhos pelos quais transcorreram essas formações podem levar os sujeitos a pensar nelas por referenciais muito distintos e que marcam modelos formativos que podem ou não reforçar os aspectos científicos ou humanísticos muito peculiares de cada campo de conhecimento.

Outro aspecto que atravessa a constituição da docência desses professores é o desconhecimento do universo escolar. $\bigcirc$ professor Ares, que iniciou sua docência no Instituto Federal da Bahia, declara que, na sua chegada à sala de aula, enfrentou o desafio de lidar com um universo distinto, com práticas e processos organizativos do trabalho docente sobre os quais não tinha qualquer conhecimento. Ele diz:

[...] diário de classe, eu não sabia como fazer aquele negócio, preencher. Meu horário aqui como docente é diferenciado, eu tenho que fazer aqueles quarenta quadrinhos separados, se não fica aquele horário de oito a meio dia e pela tarde, noite. [...] Então, eu cheguei muito cru, na verdade eu não fui formado para ser professor, então assim, tinha coisas básicas desde o preenchimento de diários até elaboração de provas, divisão de pontuação, o que é que eu podia cobrar, eu não sabia nada disso. [...] O que eu aprendi como docente foi dentro do instituto mesmo. Olha, no começo teve uma colega minha que foi bastante [...] Então ela me orientou bastante, principalmente com o público da manhã, como devo me comportar, até onde eu poderia (ARES, 2014).

A descrição do professor Ares demonstra como o processo identitário passa também pelo controle do próprio trabalho, pela capacidade de autonomia para desenvolvê-lo. Afirma que não compreendia as "coisas básicas", portanto, o universo, as demandas cotidianas que atravessam o trabalho do professor eram desconhecidas por ele. Constituir-se como docente também implicou ao professor uma formação que está na dimensão procedimental do fazer do professor, que atinge o domínio dos processos burocráticos que registram a organização e a cotidianidade do trabalho do docente.

Em sua narrativa, o professor Ares ainda demonstra como sua formação docente foi talhada dentro do instituto. Com os pares, foi descobrindo que a profissão requer saberes que atravessam modos de agir com os alunos, atitudes diferenciadas considerando o universo para o qual se leciona, assumindo, 
assim, uma perspectiva formativa que não se define, apenas, num currículo formal prescrito pelas instituições de formação de professor.

É no processo de ir produzindo a docência e as práticas cotidianas escolares que os docentes bacharéis vão se formando. Pensar essa formação como um construto cotidiano implica refletir como a dimensão da heteroformação atravessa a vida docente na escola. Na experiência produzida pelos professores, fica muito evidenciado como o aprender com outro, possibilita uma aprendizagem significativa e uma potencialidade de deslocamentos pessoais e profissionais.

Assim, há também um processo de reconhecimento de si durante a narrativa que caracteriza o movimento de autoformação, na medida em que se reflete como o outro proporcionou uma mobilização de conhecimentos e geração de saberes da prática docente.

Fica visível que a experiência adquirida no cotidiano escolar com os pares é um campo formativo de produção de significações e sentidos para o exercício da profissão, mas esse processo é conflitado com os modos como esses sujeitos transitam com os conhecimentos específicos de suas áreas. Há que se pensar em um movimento em que se tornar professor é conjugado com a experiência produzida no cotidiano escolar e no domínio das ações por meio das trocas com as experiências de sujeitos sócio-históricos.

A consciência de que a historicidade atravessa a condição identitária leva a pessoa ao desafio de sua formação, que é de atualização do sujeito em sua condição de devir e de se objetivar diante das condições históricas. Essa consciência propõe uma tensão permanente entre os desejos, aspirações individuais e as transformações e exigências sociais. Portanto, ter consciência de si é a integração/interface de conhecimentos, representações, atribuição de sentidos, tomada de consciência de suas potencialidades, concretização e intencionalidade de um projeto e transformação permanente do ser.

Nesse âmago, a experiência do professor Hefesto-Andejo revela como as marcas da vida escolar são evocadas como possibilidade para a constituição do perfil docente, produzindo imagens de si como professor, e que a consciência desse processo implica uma atitude formativa.

Agora, a experiência formativa mais importante para docência foi ter sido aluno [... Mas, não tem jeito! Você vai derramar na sala de aula aquilo que você recebeu como modelo. E isso é um grande 
problema porque de uma época para outra os paradigmas vão mudando. Então eu, nós, somos frutos daquela geração onde o professor ministrava um conteúdo diretivo. Você tinha que repetir a cartilha. E eu acho que se eu for infelicitado pela reprodução desse modelo em algum momento não é por culpa minha. Eu não procuro fazer as coisas dessa forma, mas respeitando o espaço de criação do próprio aluno como sujeito (HEFESTO-ANDEJO, 2014).

Na sua narrativa, Hefesto-Andejo observa em si uma imagem docente, a qual refuta, dizendo que busca fazer diferente, respeitando o espaço de criação dos alunos. Todavia, o mesmo professor admite que a sua experiência foi com professores que ministravam conteúdos diretivos e que a experiência como aluno é importante para a docência.

Assim, assume que a experiência escolar e acadêmica como aluno é um elemento constituidor da sua forma de ser e pensar-se professor. Nesse sentido, quanto mais um professor na iniciação na docência for submetido ao compartilhamento, reflexão e compreensão sobre suas influências e necessidades iminentes no exercício da profissão, será possível construir uma identidade profissional fincada em bases teóricas e experiências que produzam um processo de autoformação.

Pode-se perceber, na fala dos professores, como o movimento de produzir a experiência na docência, pensar sobre ela foi fundamental para que estes ressignificassem os conhecimentos construídos em diversos campos e transformá-los em saberes experienciais constitutivos dos modos de viver a profissão. Assim, o professor Hefesto-Andejo ainda relata que,

Eu não perdia uma capacitação interna dentro da universidade! Então, aparecia era um final de semana eu estava lá, não interessa quatro horas, oito, ou vinte e quatro, mas eu estava em todas as capacitações. De modo prático se isso me ajudava a resolver alguma questão de organização do meu trabalho em sala de aula, mesmo que alguma tivesse tido esse objetivo, não era essa parte que me interessava. Então, o que mais interessava nessas capacitações? Era eu estar em contato com pessoas, trazendo ideias novas que eram de outras áreas de formação e estar podendo interagir com elas. [...] E outra coisa, a gente tem que fazer costura entre essas coisas. Não pode ser uns departamentos separados da vida. Não podem ser conhecimentos da maneira como são ministrados para gente dentro da universidade (HEFESTO-ANDEJO, 2014). 
Em seu relato, o professor mostra como se mobilizou para ir superando as dificuldades e limitações do seu processo formativo e como a reflexividade se faz presente nesse movimento. A busca por formação continuada revela-se como um movimento constante que declarou ter realizado, salientando um aspecto importante para essa dimensão formativa, que é a necessidade de integração entre os conhecimentos.

Ao afirmar que o mais interessante era aprender coisas novas, mas que era salutar "fazer costura entre essas coisas", o professor defende uma condição para que esse processo seja efetivo e se integre à vida e não se reproduza o modo como foi realizada a sua formação na universidade.

$\bigcirc$ professor Hefesto-Andejo apresenta que, após sua chegada à sala de aula, o processo formativo foi fundante para ir produzindo sua identidade como docente. Em acordo com essa proposição, vale salientar que é muito importante que a chegada do professor seja alimentada por uma política de formação dentro da instituição, assumindo o eixo da profissionalização docente marcado pelo respeito à experiência, aos dilemas da cotidianidade escolar e aos modos de ser e viver a profissão.

É fundamental considerar a singularidade de cada pessoa-professor, 106 seus tempos, seus modos de fazer e de compreender sua profissão, sobretudo, no perfil que é previsto para professores que atuam nos Institutos Federais. A entrada de professores nos institutos leva em consideração a titularidade, o grau de formação, os resultados objetivos dos processos seletivos ${ }^{3}$, homogeneizando sujeitos diversos que constituem uma rede de complexidade. Entretanto, não são consideradas, nem enquanto política de ingresso, nem como política de formação continuada, as diferenças e as particularidades dos docentes. Ao contrário, o professor se despersonifica, torna-se mais um em meio a tantos, identificado por sua matéria de ensino, sua titularidade e sua capacidade produtiva.

Em face do exposto, é fundamental pensar em uma política de formação inicial para professores que já atuam na educação profissional, visto que estes sujeitos assumiram a condição de docência sem uma formação adequada para o exercício da profissão docente, entretanto, dois aspectos precisam ser considerados.

$\bigcirc$ primeiro é que o exercício da docência para os profissionais da área técnica, formada essencialmente por bacharéis, exige que esses 
professores sejam formados em suas áreas técnicas, portanto, não seria uma licenciatura como primeira formação que os habilitaria ao exercício da função docente no campo da formação técnica na Educação Profissional Técnica.

segundo aspecto é o fato de que esses professores, ao se depararem com a docência, evocam suas experiências pessoais formativas e vão ressignificando esses conhecimentos e novos conhecimentos adquiridos na prática educativa. Assim, tais saberes e sentidos sobre a profissão docente não podem ser negligenciados em um projeto de formação inicial para professores.

Verifica-se, nesse contexto, que o desafio formativo para os bacharéis está posto, pois esses profissionais chegam à docência sem a construção de discussões sobre currículo, avaliação, planejamento, relação entre ensino e aprendizagem, entre outros aspectos específicos do processo formativo para professores.

As narrativas feitas por Hefesto-Andejo e Ares mostram que a falta de uma fundamentação, da construção prévia de uma compreensão sobre a dinâmica do trabalho docente frente aos aspectos de tempo e espaço do exercício da profissão, bem como as demandas burocráticas como cadernetas e outros instrumentos, trazem dificuldades para a iniciação na docência desses professores.

Apesar de demonstrarem em suas narrativas que tais aprendizagens podem ocorrer, na prática, isso não garante a produção de um fazer autônomo. Portanto, valorizar a experiência é fundante no projeto de formação, mas é preciso considerar o suporte teórico-metodológico e a dimensão reflexiva que um processo formativo articulado pode gerar no exercício da docência, ao produzir saberes, capazes de ressignificar os conhecimentos docentes.

\section{Considerações finais}

As narrativas de vida-formação aqui evidenciadas revelam como as experiências dos sujeitos constituem suas docências. Apesar de algumas interfaces produzidas pela leitura hermenêutica da pesquisa, cabe destacar que os processos subjetivados desenvolvem modos particulares de cada pessoa-professor exercer sua profissão.

Desse modo, as narrativas mostram os sentidos produzidos pelos sujeitos ao longo de suas trajetórias pessoais sobre a condição de ser docente. 
Ademais, revelam os acontecimentos que os levaram ao exercício da docência, atestando que a história profissional e formativa de cada pessoa é a sua própria história de vida. Nesse sentido, é fundamental pensar o percurso de vida-formação como âmago da constituição profissional, assim a vida do sujeito é seu espaço-tempo de constituição profissional.

No âmbito das histórias de vida-formação aqui reveladas as experiências familiares, escolares, acadêmicas formam um tecido que imprime sob cada um sujeito um ethos, uma condição de exercício da docência, pois tais experiências condensam passado e futuro, aspectos internos e externos que, no processo de reflexividade, revelam-se produtores da autoformação desses sujeitos que, ao se imbuir de si mesmos assumem, autonomamente, a escrita de suas docências.

Nessa perspectiva, o processo analisado converge com a perspectiva de Pineau (2014) ao indicar que o movimento de ecoformação, heteroformação e autoformação se transversalizam na constituição da subjetividade de uma pessoa. Converge ainda com a perspectiva de que as narrativas são processos produzidos a partir das experiências dos sujeitos e produzem um movimento de reflexividade que expõe a pessoa a um processo autoformativo.

Ainda como resultado da pesquisa, as entrevistas revelaram o quão importante se faz pensar uma política de formação docente que coadune os referenciais teórico-metodológicos, apropriados ao fazer do professor, mas, também, considere as experiências formadoras da identidade docente.

\section{Notas}

1 Em concordância com as exigências do Comitê de Ética, utilizamos pseudônimos considerando o sigilo sobre a identidade dos sujeitos, ação prevista no Termo de Consentimento Livre e Esclarecido aprovado pelo Parecer 540.217 do Comitê de Ética da Universidade do Estado da Bahia atendendo à resolução 196/96 do Conselho Nacional de Saúde.

2 As Diretrizes Curriculares Nacionais para Formação de Professores para Educação Básica foram promulgadas pela Resolução do Conselho Nacional de Educação, n 1, de 18 de fevereiro de 2002.

3 Os últimos editais de concurso público para cargo de professor efetivo, bem como para cargos de professores temporários e substitutos, solicitam que a formação para docentes seja de licenciados ou bacharéis, com especialização, mestrado ou doutorado na área ou áreas afins, sem fazer qualquer menção a uma formação pedagógica, com exceção das licenciaturas. 


\section{Referências}

APOLO. Entrevista narrativa. Ithéus (Bahia), 10 jun. 2014.

ARES. Entrevista narrativa. Ihéus (Bahia), 16 jun. 2014.

ARTEMIS. Entrevista narrativa. Ithéus (Bahia), 9 jun. 2014.

BONDÍA, Jorge Larrosa. Notas sobre a experiência e o saber da experiência. Revista Brasileira de Educação, Rio de Janeiro, n. 19, p. 20-28, jan./abr. 2002,.

BRASIL, Ministério da Educação. Diretrizes Curriculares para a Formação de Professores da Educação Básica. Brasília: Conselho Nacional de Educação, 2002.

Referenciais Curriculares Nacionais para os Cursos de Bacharelados e Licenciaturas. Brasília: Secretaria de Educação Superior, 2010.

DELORY-MOMBERGER, Christine. A condição biográfica: ensaios sobre a narrativa de si na modernidade avançada. Tradução Carlos Galvão Braga, Mara da Conceição Passeggi, Nelson Patriota. Natal: EDUFRN, 2012

GATTI, Bernadete Angelina. A formação dos docentes: o confronto necessário professor $X$ academia. In: GARCIA, Walter (Org.). Bernadete Angelina Gatti: educadora e pesquisadora. Belo Horizonte: Autêntica, 2011.

Os professores e suas identidades: o desvelamento da heterogeneidade In: GARCIA, Walter (Org.). Bernadete Angelina Gatti: educadora e pesquisadora. Belo Horizonte: Autêntica, 2011 la.

HEFESTO-ANDEJO. Entrevista narrativa. Ithéus (Bahia), 30 maio. 2014.

JAY, Martin. Cantos de experiência: variaciones modernas sobre um tema universal. Buenos Aires: Paidós, 2009.

NÓVOA, Antônio. Os professores e as Histórias da sua Vida In: NÓVOA, Antônio (Org.). Vidas de professores. 2. ed. Porto, Portugal: Porto Editora, 2007.

PINEAU, Gaston. A autoformação no decurso da vida: entre a hetero e a ecoformação. In: FINGER, Mathias; NÓVOA, Antônio. O método (auto)biográfico e a formação. Tradução Maria Nóvoa. 2 ed. Natal: EDUFRN, 2014.

RAMALHO, Betânia leite; NÚÑ̃EZ, Isauro; GAUTHIER, Clermont. Formar o professor, profissionalizar o ensino: perspectivas e desafios. Porto Alegre: Sulina, 2004. 
RIOS, Jane Adriana Vasconcelos Pacheco. Narrativas e memórias da profissão docente no meio rural. In: FONTOURA, Maria Helena, LELIS, Isabel Alice Oswald Monteiro, CHAVES, Iduina Mont'Alverne (Org.). Espaços formativos, memórias e narrativas. Curitiba: CRV, 2014.

SOUZA, Elizeu Clementino de. Diálogos Cruzados sobre pesquisa (auto)biográfica: análise compreensiva-interpretativa e política de sentido. Educação, Santa Maria, v. 39, n. 1, jan./ abr. 2014.

SOUZA, Francisco e NASCIMENTO, Vivianne. Bacharéis professores: um perfil docente em expansão na Rede Federal de Educação Profissional Tecnológica. In: MOURA, Dante Henrique (Org.). Produção de conhecimento, políticas públicas e formação docente em educação profissional. Campinas: Mercado de Letras, 2013.

Profa. Ms. Graziela Ninck Dias Menezes Instituto Federal da Bahia | Campus Ithéus Instituto Federal de Educação da Bahia Grupo de Pesquisa Docência, Narrativas e Diversidade na Educação Básica - DIVERSO

Grupo de Pesquisa Ciência, Tecnologia e Meio Ambiente Linha: Núcleo de Estudos Urbanos e Culturais do Sul da Bahia | Eixo Ilhéus-ltabuna E-mail | ninckgdm@gmail.com

Profa. Dra. Jane Adriana Vasconcelos Pacheco Rios Universidade do Estado da Bahia Departamento de Educação Programa de Pós-Graduação em Educação e Contemporaneidade Programa de Pós-Graduação em Educação e Diversidade Líder do Grupo de Pesquisa Docência, Narrativas e Diversidade na Educação Básica - DIVERSO Grupo de Pesquisa em (Auto)biografia, Formação e História Oral - GRAFHO E-mail | jhanrios1@yahoo.com.br

Recebido 8 set. 2015 Aceito 5 jul. 2016 